\title{
Исследование микроструктуры бетонов при воздействии кислых сред методом электронной микроскопии
}

\author{
Белогурова Т.П. ${ }^{1}$, Нерадовский Ю.Н. ${ }^{2}$, Беляевский А.Т. ${ }^{1}$ \\ ${ }^{1}$ Институт химии и технологии редких элементов и минерального сырья им. И.В. Тананаева КНЦ РАН, \\ Anamumbl, t.belogurova@ksc.ru \\ ${ }^{2}$ Геологический институт КНЦ РАН, Anamиты, nerad@geoksc.apatity.ru
}

Аннотация. Исследованием структуры бетонов с заполнителем из уртита при воздействии кислых сред методом электронной микроскопии установлено, что в течение 1.5 лет испытаний главные минеральные фазы уртита в соединении с цементной матрицей не подверглись изменениям. Нефелиновый заполнитель, благодаря повышенной активности к гидроксиду кальция, интенсифицирует процессы фазообразования вторичных продуктов, способствуя уплотнению структуры цементного камня и замедлению диффузии агрессивных агентов.

Ключевые слова: микроскопические исследования, уртит, бетон, кислая среда, структура, гидратация.

\section{Investigation of the microstructure of concrete under the influence of acidic media by electron microscopy}

\author{
Belogurova T.P. ${ }^{1}$, Neradovsky Y.N. ${ }^{2}$, Belyaevsky A.T. \\ ${ }^{1}$ I.V.Tananaev Institute of Chemistry and Technology of Rare Elements and Mineral Raw Materials of the Kola Science \\ Centre, RAS, Apatity, t.belogurova@ksc.ru \\ ${ }^{2}$ Geological Institute of the Kola Science Centre, RAS, Apatity,nerad@geoksc.apatity.ru
}

\begin{abstract}
The study of the structure of concrete with an urtite aggregate under the influence of acidic media by electron microscopy revealed that during 1.5 years of testing, the main mineral phases of urtite in combination with the cement matrix were not changed. The nepheline aggregate, due to its increased activity to the calcium hydroxide, intensifies the processes of phase formation of secondary products, contributing to the compaction of the cement stone structure and slowing down the diffusion of aggressive agents.
\end{abstract}

Key words: microscopic studies, urtite, concrete, acidic environment, structure, hydration.

Основными разновидностями вскрышных пород рудников АО «Апатит» при добыче апатитонефелиновых руд являются уртиты. Применение данных пород в строительстве ограничивается повышенным содержанием в их составе нефелина. Ранее проведенными исследованиями установлено, что данные породы относятся к плотным и прочным, с низкими значениями водопоглощения и истираемости и могут служить сырьевым источником заполнителей для тяжелых бетонов (Белогурова и др., 2004). Результаты испытаний уртитов и уртитового щебня в средах с повышенным содержанием ионов $\mathrm{Cl}^{-}, \mathrm{SO}_{4}^{2-}$ и $\mathrm{NO}_{3}^{-}$свидетельствуют о достаточной стойкости этих материалов в жидких агрессивных средах (Белогурова и др., 2019). Изучением бетонов с заполнителем из уртита в жидких агрессивных средах показано, что нефелинсодержащий заполнитель способствует повышению их коррозионной стойкости (Белогурова и др., 2020). Целью настоящих исследований являлось изучение поведения различных минералов уртита при взаимодействии с цементом в агрессивных средах методом электронной микроскопии.

Внутренняя структура бетонов, подвергшихся воздействию различных жидких сред, изучалась на полированных образцах. Снимки выполнялись в отраженных электронах на сканирующем электронном микроскопе SEM LEO-1450 в ГИ КНЦ РАН.

На рисунке 1 приведены фото образцов бетонов нормального твердения на уртите и уртите с золой после 1.5 лет воздействия кислотных растворов. На всех фото отчетливо прослеживается полиминеральный характер уртита, включающий нефелин, титанит, пироксен, ильменит и другие минералы. В исследованиях особое внимание уделялось изучению реакции основного минерала уртита - нефелина на воздействие жидких сред и его поведению в зоне контакта с цементом.

Анализ представленных фотографий в целом позволяет констатировать, что практически все представленные образцы бетона имеют достаточно плотную структуру с ярко выраженным контак- 

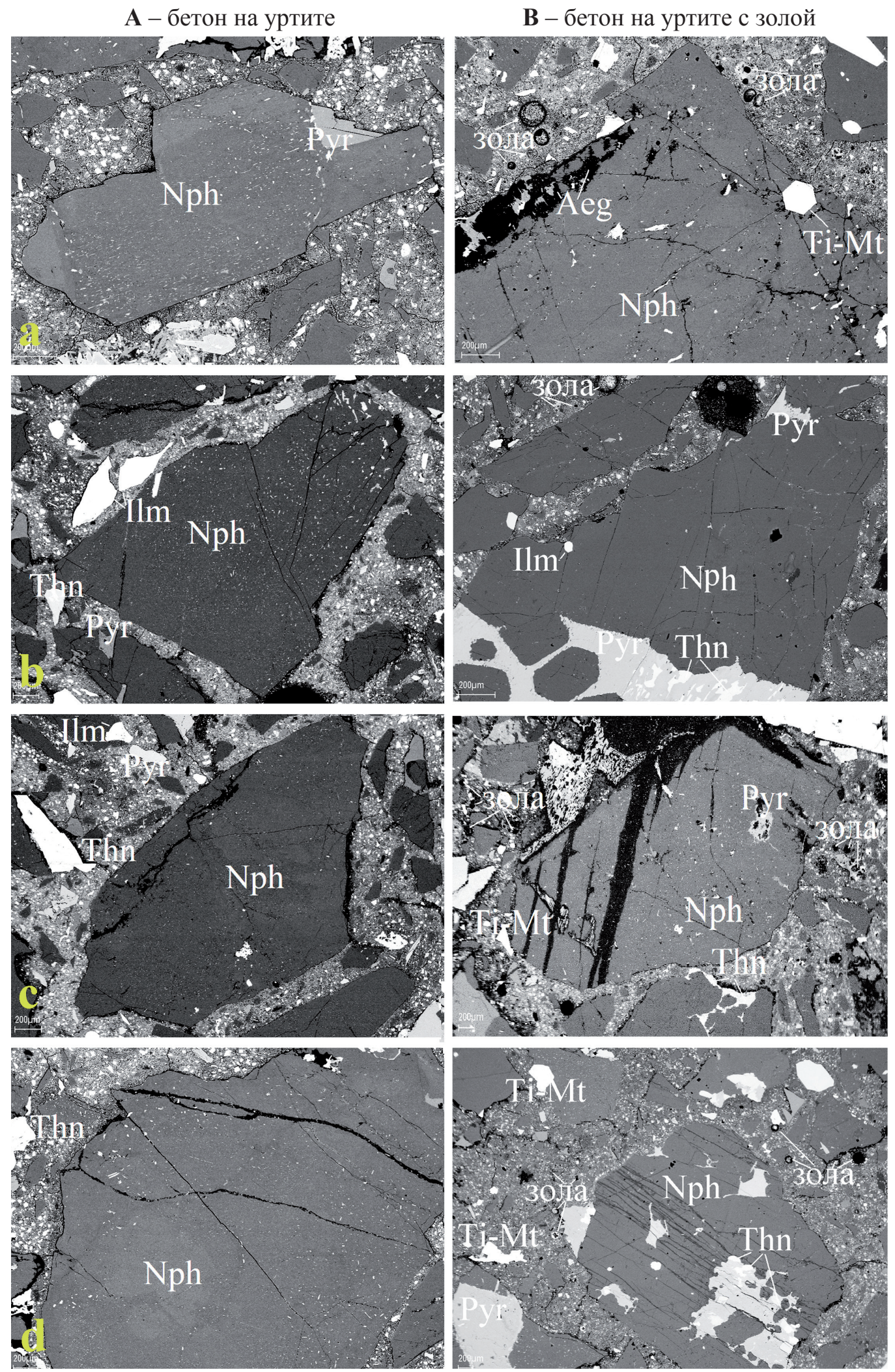

Рис. 1. Бетона на уртите (А) и уртите с золой (В) после 1.5 года хранения в: a - дистиллированной воде, $\mathrm{b}$ - хлористой среде, c - азотнокислой среде, d - сернокислой среде; $\mathrm{Nph}$ - нефелин, $\mathrm{Pyr}$ - пироксен, Ti-Mt - титаномагнетит, Ttn - титанит, Aeg - эгирин. (SEM LEO-1450).

Fig. 1. Concrete urtite (A) and urtite with ash (B) after 1.5 years of storage in: a - distilled water, $b$ - chloride environments, $\mathrm{c}$ - nitrate medium, $\mathrm{d}$ - sulfate medium; Nph - nepheline, Pyr - pyroxene, Ti-Mt - titanomagnetite, Ttn - titanite, Aeg - aegirine. (SEM LEO-1450). 
том заполнителя с цементом. При этом бетон на уртите с золой имеет более плотную контактную зону без зазоров и трещин. Зерна нефелина на всех представленных фото не имеют видимых повреждений от действия растворов.

При детальном изучении образцов видно, что на рисунке 1 , A-a и B-b зерна нефелина представлены в виде абсолютно свежих, не затронутых процессами выветривания кристаллов с природными включениями пироксена, титанита и ильменита. На остальных фото прослеживаются микротрещины по нефелину, носящие как технологический характер (образовавшиеся при дроблении породы, испытании бетона на прочность или при подготовке образцов), так и природное происхождение (связанные с процессами естественной минерализации в нефелине). Все эти трещины сухие, не содержащие вторичных минералов; проникновение по ним растворов солей не наблюдается.

На фото также представлены образцы измененного нефелина, по которому в результате шпреуштейнизации развивались вторичные фазы эгирин-авгита, пироксена, титанита (рис. 1, B-a, А-c, B-d). Поскольку явление шпреуштейнизации характерно для Хибинских апатито-нефелиновых руд, в уртитах этих месторождений нефелин часто бывает изменен. Это было учтено при проведении эксперимента. На основании проведенных микроскопических исследований отдельных минералов непосредственно в зернах заполнителя и по краям на контакте с цементом установлено, что ни нефелин, ни другие породообразующие минералы уртита не претерпели каких-либо вторичных изменений, растворения или коррозии от действия агрессивных растворов.

Вместе с тем, на фото (рис. 1, A-a-d) на отдельных участках контактной границы зерна нефелина с цементом прослеживаются затемненные участки, свидетельствующие о неплотном сцеплении минерала с цементом. Эти дефекты могли быть вызваны либо технологическими факторами при изготовлении образцов бетона, либо динамическими нагрузками при испытании бетона, либо механическими повреждениями при полировке образцов абразивным материалом в силу различной плотности минерала и цемента. Однако, именно на этих участках возможны какие-либо изменения, связанные с укреплением или ослаблением контактной зоны цемент-заполнитель. Возможности настоящих микроскопических исследований не позволяют установить процессы, происходящие в этих зонах. Ранними исследованиями (Крашенинников и др., 1989) было показано, что на границах цемент-заполнитель возможно появление участков с уплотненной структурой за счет образования так называемой «реакционной каймы», свидетельствующей о происходящих химических процессах в зоне контакта.

Изучение процессов, происходящих в контактной зоне бетонов, проводилось с помощью цифрового сканирующего электронного микроскопа SEM LEO-420. В задачу исследований входило изучение новообразований, появившихся в контактной зоне цемента с заполнителем и в порах бетонов под воздействием агрессивных растворов.

На рисунке 2 представлены фото сколов поверхностей образцов бетонов на уртите после 1.5 года воздействия кислых сред.

На снимках видно, что образцы бетона имеют развитую контактную поверхность, на которой представлены новообразования различного состава - от геля кремнекислоты до сферических сростков тонкоигольчатых кристаллов гидросиликатных и гидроалюминатных соединений. В образцах бетонов, хранившихся в дистиллированной воде и в хлористой среде наблюдается большая доля слабо окристаллизованных гидросиликатов кальция, которые формируют сплошную сетку из новообразований, в результате чего устраняются микродефекты структуры на микроуровне. В сернокислой и азотнокислой средах на границе уртита с цементной матрицей четко прослеживается образование игольчатых сферических кристаллов низкоосновных гидросиликатов кальция типа эттрингита и плоскопризматических кристаллов портландита. Видно, что в данных средах образуется значительно большее количество контактов срастания заполнителя с цементной матрицей, упрочняя структуру бетона контактной зоны. Следов образования нетипичных для гидратации цемента фаз, коррозионного поражения или растворения минералов уртита на контакте с цементом не обнаружено.

На рисунке 3 при большом увеличении видно, что аналогичные новообразования накапливаются и в порах цемента. После 1.5 года воздействия дистиллированной воды (рис. $3, \mathrm{~A}$ ) в поре бетона на уртитовом заполнителе образовался слой, состоящий из мелкокристаллических гелеобразных гидратных соединений и тонкоигольчатых кристаллов гидросиликатов кальция, способствующих замоноличиванию поры уплотнению структуры цементного камня. 
Под воздействием растворов солей соляной, серной и азотной кислот в порах бетона на уртите образовалась мелкокристаллическая сотообразная структура уплотняющих и упрочняющих гелеобразных гидратных соединений (рис. 3, B-D), идентичных гидроалюминатам и гидросиликатам кальция. В работах (Белогурова и др., 1990; Рахимбаев и др., 2011) показано, что уртиты являются химически активными породами. При этом уртит в качестве активного заполнителя в целом не изменяет хода основных химических взаимодействий при гидратации цемента, но скорость протекания реакции значительно повышается. Продукты гидратации поглощаются быстрорастущими кристаллами и не успевают образовывать новые оболочки, что способствует интенсивному взаимодействию в системе и формированию монолитного каркаса. В результате при массовом образовании кристаллогидратов на поверхности негидратированных ядер создается плотная оболочка, которая со временем еще более уплотняется, обеспечивая достаточно плотное зарастание пространственного объема и формирование слитной структуры композита с высокими физико-механическими свойствами.

Таким образом, изучением структуры бетонов на уртитах с помощью электронной микроскопии подтверждено, что в образцах бетонов при воздействии кислых сред происходит ускорение процесса образования вторичных продуктов. Данные новообразования накапливаются в зоне контакта цемента с заполнителем и порах бетона, уплотняя структуру цементного камня и замедляя диффузию агрессивных агентов (Рахимбаев, 2012).

Проведенными исследованиями установлено, что структура бетона на нефелинсодержащих заполнителях - уртитах является более прочной и плотной за счет улучшенной контактной зоны. Полученные результаты испытаний свидетельствуют о достаточно высокой стойкости бетонов на
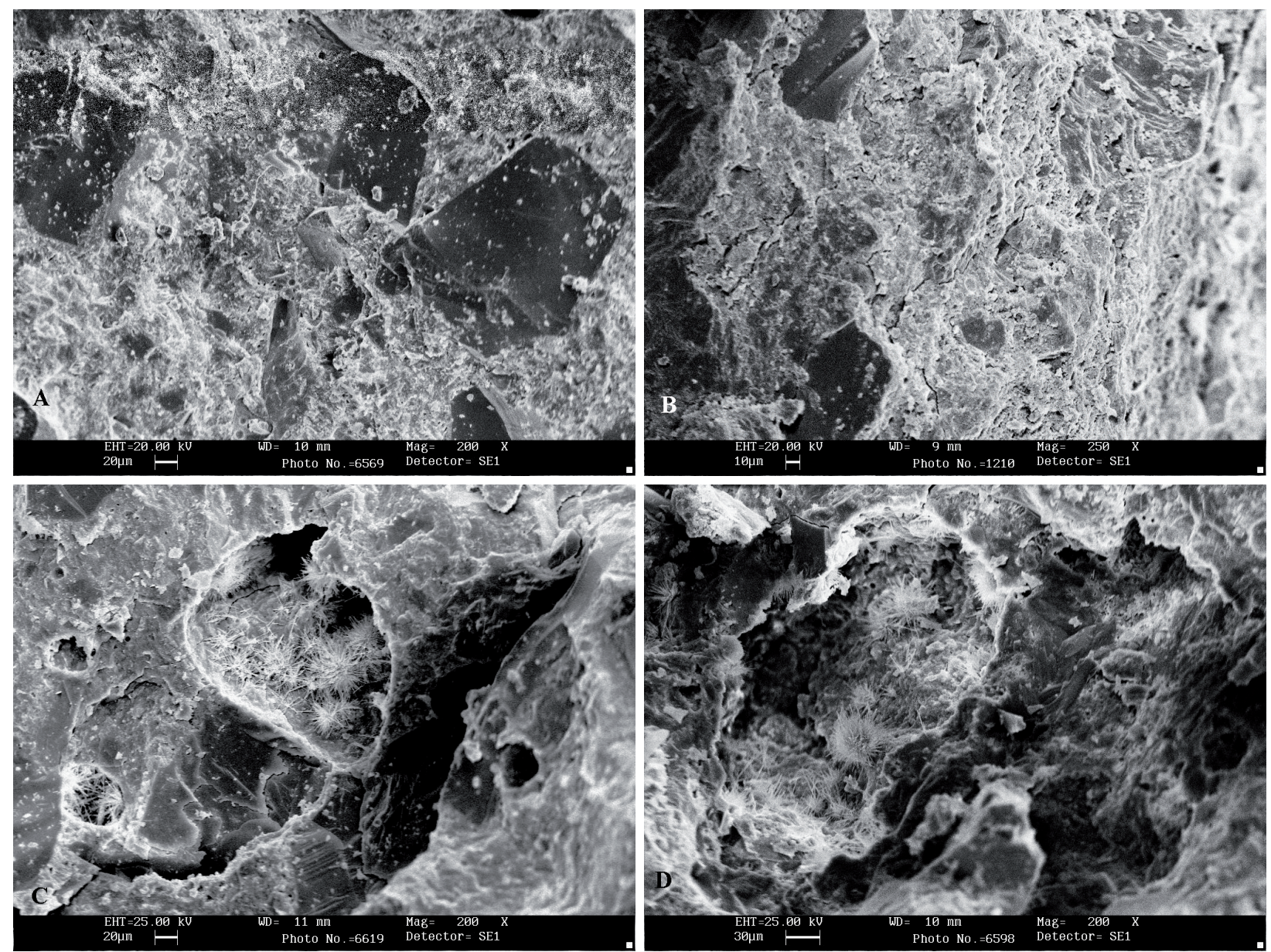

Рис. 2. Микроструктура бетонов на уртите после 1.5. года воздействия: А - дистиллированной воды, В - хлористой среды, C - сернокислой среды, D - азотнокислой среды (SEM LEO 420). Увеличение 200.

Fig. 2. Microstructure of concrete on urtite after 1.5 years of exposure: A-distilled water, B - chloride medium, C-sulfuric acid medium, D-nitric acid medium (SEM LEO 420). Increase 200. 

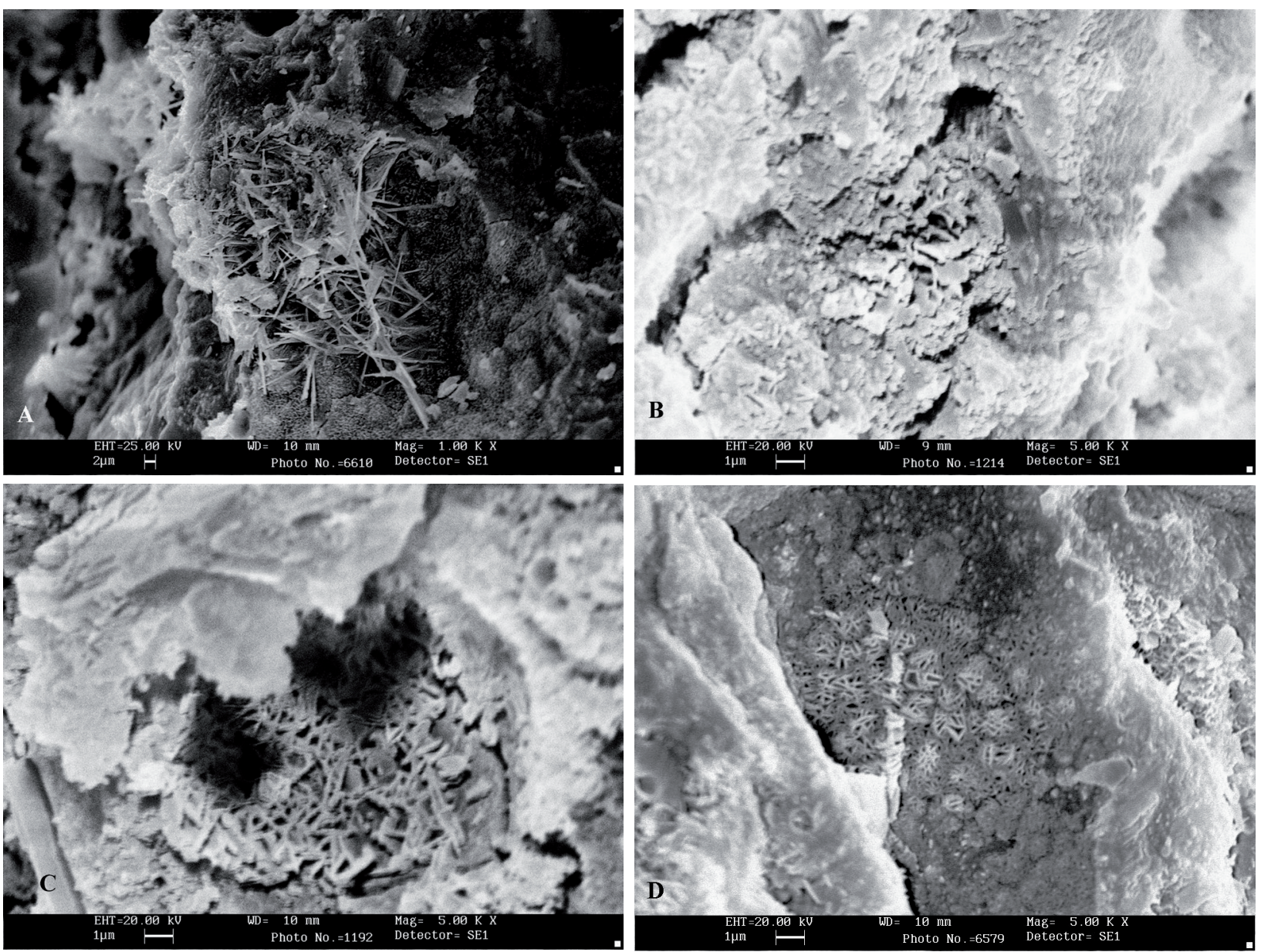

Рис. 3. Новообразования в порах бетона на уртите после 1.5. года воздействия: А - дистиллированной воды, В - хлористой среды, C - сернокислой среды, D - азотнокислой среды (SEM LEO 420). Увеличение 1000 (A) и 5000 (B-D).

Fig. 3. Neoplasms in the of pores concrete on urtite after 1.5 years of exposure: A-distilled water, B - chloride medium, C-sulfuric acid medium, D-nitric acid medium (SEM LEO 420). Increase of 1000 (A) and 5000 (B-D).

нефелинсодержащих заполнителях в кислых средах, что позволяет использовать уртиты в качестве заполнителей бетонов.

Работа выполнена в рамках темы НИР ИХТРЭМС КНЦ РАН № 0226-2020-0068.

\section{Литература}

1. Белогурова Т.П., Крашенинников О.Н. Утилизация вскрышных пород Хибинских апатитонефелиновых месторождений в строительстве // Строительные материалы. 2004. № 6. С. 32-35.

2. Белогурова Т.П., Крашенинников О.Н., Рояк Г.С. и др. О реакционной способности вскрышных пород рудников ПО «Апатит» // Физико-химические основы переработки и применения минерального сырья. Апатиты: КНЦ АН СССР. 1990. С. 32-35.

3. Белогурова Т.П., Нерадовский Ю.Н., Беляевский А.Т. Коррозионная стойкость бетонов с заполнителем из уртита // Труды Ферсмановской научной сессии ГИ КНЦ РАН. 2020. № 17. С. 49-54.

4. Белогурова Т.П., Нерадовский Ю.Н., Компанченко А.А. Коррозионная стойкость уртитов в жидких агрессивных средах // Труды Ферсмановской научной сессии ГИ КНЦ РАН. 2019. № 16. С. $23-27$.

5. Крашенинников О.Н., Белогурова Т.П., Цветкова Т.В. Влияние минерального состава уртитового заполнителя и условий твердения бетона на формирование контактной зоны // Комплексное использование минерального сырья в строительных и технических материалах. Апатиты: КНЦ АН СССР, 1989. С. $22-25$.

6. Рахимбаев Ш.М. Кинетика процессов кольматации при химической коррозии цементных систем // Бетон и железобетон. 2012. № 6. С. 16-17.

7. Рахимбаев Ш.М., Толыпина Н.М. Кислотостойкий бетон с эффективным активным заполнителем // Бетон и железобетон. 2011. № 4. С. 24-26. 